\title{
Significados del trabajo en mujeres que realizan trabajos productivo y reproductivo
}

\author{
Meaning of working in women who do productive and \\ reproductive works
} \section{OPBicogeretre}

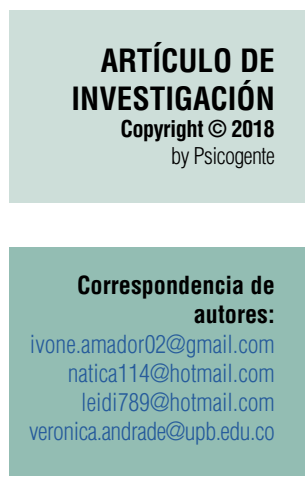

Recibido: $10-07-17$ Aceptado: $23-03-18$ Publicado: 08-01-19

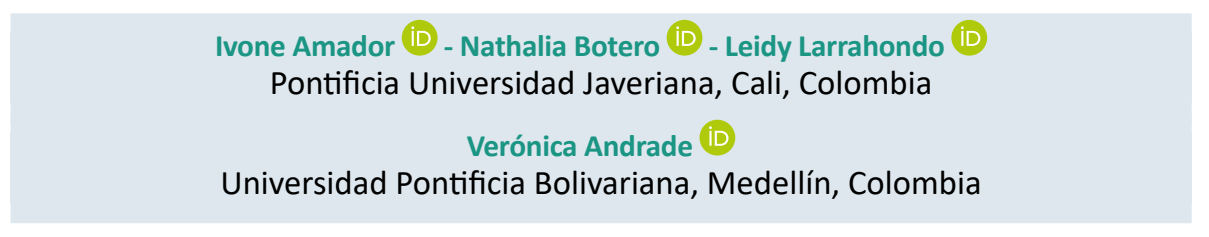

Resumen

Objetivo: El presente artículo de investigación buscó analizar el significado del trabajo en mujeres con trabajo productivo (MTP) y reproductivo (MTR) en la ciudad de Cali, Colombia. Para ello se consideraron las subcategorías: centralidad, normas sociales, valores laborales, tipo de actividad realizada y trayectorias laborales.

Método: Se realizó una investigación cualitativa con diseño fenomenológico. Se empleó una guía de entrevista semiestructurada. Participaron 6 mujeres con MTP y 6 mujeres con MTR contactadas por bola de nieve, entre los 30 y 40 años.

Resultados: Se encontró que las MTP presentan mayor centralidad que las MTR; los derechos de las MTP están centrados en aspectos legales y los de las MTR, en aspectos simbólicos asociados al reconocimiento de los familiares. Los deberes de las MTP se enfocan en sus funciones laborales y los de las MTR, en todas las labores cotidianas del hogar. Los valores laborales de las MTP enfatizan en mayores sueldos, mayor independencia, horario flexible, mejor trato y ocupar posiciones de dirección; en las MTR se destaca el ganar un sueldo para suplir necesidades propias y del hogar, y contar con más participación por parte de pareja y familiares.

Conclusión: Ambos significados se relacionan con aspectos de género sobre la división sexual del trabajo como algo natural, incluso para las MTP, donde la mujer es la responsable del trabajo reproductivo, viéndose la participación de la pareja como una ayuda o favor, y no como una responsabilidad compartida.

Palabras clave: Significados del trabajo, Trabajo productivo, Trabajo reproductivo, Labor reproductiva, Mujeres.

Abstract

Objective: This paper analyzes the meaning of working in Women with Productive Work (WPW) and Women with Reproductive Work (WRW) in Cali city, Colombia. To achieve this purpose, four dimensions proposed by the MOW (1987) were studied: centrality, social norm and work values, kind of work and work trajectories.

Method: A qualitative research was carried out based on phenomenological design. Semi-structured interview guides. Six WPW and six WRW were chosen randomly with an age among 30 and 40 years.

Results: It was found that the WPW present more centrality than the WRW; also, the WPW's rights are based on legal aspects, while WRW's rights are based on symbolic values associated to the recognition of their relatives. The duties of the WPW are focused on the specific function of their job's nature, meanwhile for the WRW their duties cover all daily tasks demanded from their household. Women with productive occupations have their work values highlighted by bigger incomes, more independency, flexible schedules and the prospect of occupying a directive position; as long as for the women with a reproductive occupation they are encouraged for getting a better income to supply their own necessities or the family's, as well as to rely on their respective partner's or family's support.

Cómo citar este artículo (APA):

Amador, I., Botero, N., Larrahondo, L. y Andrade, V. (2019). Significados del trabajo en mujeres que realizan trabajos productivo y reproductivo. Psicogente 22(41), 1-36. https://doi.org/10.17081/psico.22.41.3302 
Conclusion: Both groups have been permeated by a default genre perspective that empowers a sexual division of the work activities, such that it is taken for granted that women are responsible for all the household activities and reproductive work even when they are performing the same productive activities as their partners, whose participation in such household activities is usually regarded as a help or even a favor, not as a shared responsibility.

Keywords: Meaning of working, Productive work, Reproductive work, Reproductive labor, Women.

\section{INTRODUCCIÓN}

En las últimas décadas se han presentado cambios sociales, políticos, económicos, tecnológicos y legales que influyen en las maneras en que las personas están manejando temas relativos al trabajo y a la familia, y a la intersección entre estas dos dimensiones (Joplin, Francesco, Shaffer \& Lau, 2003). Dichos cambios demandan repensar los modos de relación que se establecen tanto en el ámbito laboral (Andrade, 2014) como en el familiar (Álvarez \& Gómez, 2011), considerando que el trabajo productivo propiamente que genere ingresos se viene convirtiendo en la fuente económica principal que promueve bienestar y supervivencia para la mayoría de las personas, tanto para hombres como para mujeres (Peiró, Prieto \& Roe, 2002).

En Colombia, en el trimestre abril-junio de 2018, el número de mujeres ocupadas fue $9^{\prime} 459.000$ y de hombres fue $13^{\prime} 130.000$. En el total nacional, la tasa de desempleo para las mujeres en el trimestre abril-junio de 2018 fue $12,2 \%$, con una tasa global de participación de $54,3 \%$ y una tasa de ocupación de $47,7 \%$. Las ramas con mayor ocupación por parte de mujeres en el trimestre abril-junio de 2018 fueron: Comercio, hoteles y restaurantes $(32,7 \%)$ y Servicios comunales, sociales y personales (31,8\%). En el trimestre abril-junio de 2017 estas proporciones fueron 32,9 \% y 30,7 \%, respectivamente (Departamento Administrativo Nacional de Estadística, 2018).

El trabajo productivo "en el sentido económico moderno (...) una actividad desplegada con vistas al intercambio mercantil y que constituye necesariamente el objeto de un cálculo contable" (Gorz, 1995, p.180) se requiere, además de las razones económicas, porque provee funciones de naturaleza psicosocial como identidad, sentido de utilidad, entre otras (Luque, Gómez \& Cruces, 2000) que favorecen el bienestar general y en particular el bienestar psicológico de quienes lo realizan. Sin embargo, además del trabajo productivo se requiere del reproductivo para dar continuidad a la especie humana, ya que las labores relativas a este ámbito siguen siendo relevantes 
para nuestra existencia (Larrañaga, Arregui \& Arpal, 2004), entendiendo este último como "el conjunto de actividades del hogar cuyo fin es satisfacer las necesidades de la familia y garantizar la reproducción biológica y social de la fuerza de trabajo" (Garazi, 2017, p.9).

Existe una línea delgada que separa al trabajo productivo del reproductivo, considerando además que dentro del hogar, algunas mujeres llevan a cabo trabajos productivos informales o de subsistencia (Garazi, 2017), o trabajos productivos no remunerados como lo señalan Gammage y Orozco (2008) en su informe para la CEPAL. Ya desde la década de los 70, Dalla Costa y Selma (1972) planteaban cómo el sistema capitalista había llevado a la destrucción de los modos en que se organizaban los grupos familiares y las comunidades existentes, al reconfigurar el rol del ama de casa que cambió para volverse un ama de cada trabajadora (working class housewife). Las autoras señalan cómo estos dos roles han querido mostrarse como separados, donde una es la mujer que se dedica a la casa y otra al trabajo, sin embargo, plantea que estos roles no son indisolubles, y abogaron por mostrar cómo las labores de lo que se conoce como trabajo reproductivo también aportan directamente a la economía y el desarrollo de los países.

El presente artículo analiza los significados del trabajo en mujeres que realizan trabajos productivo y reproductivo en la ciudad de Cali, entendiendo como productivo aquel derivado de actividades económico-productivas que generan ganancias en dinero o especie, y como reproductivo aquel "proceso continuo que reemplaza y sostiene la fuerza de trabajo y el tejido social" (Gammage \& Orozco, 2008, p.12). Pese a tener claro que estas categorías pueden traslaparse considerando que existen mujeres cuya principal actividad es el trabajo reproductivo, pero que como se mencionó, pueden llevar a cabo labores de naturaleza productiva en el hogar, así como mujeres que declaran estar en trabajo productivo pero que claramente realizan también trabajo reproductivo, se consideró principalmente trabajar sobre la dicotomía o polaridad productivo-reproductiva en función de lo que las propias participantes declararon como la actividad laboral principal a la que se dedican, sin desconocer que estos polos ciertamente funcionan como un continuo.

Lo anterior debido al incremento de la participación de la mujer en el mercado de trabajo formal (Guzmán \& Dalén, 2013) con aumento de las horas dedicadas al trabajo remunerado (Abramo, 2004), y a su vez al refuerzo de 
su participación en el mercado informal (Venegas, 2010; Medialdea, 2016), donde las mujeres hoy realizan con mayor regularidad trabajos productivos y/o reproductivos. Las que deciden insertarse o mantenerse en trabajos productivos lo hacen por exigencias económicas, búsqueda de autonomía (Todaro, 2015), y por el acceso a la educación superior (Montaño, 2007). El que algunas mujeres opten por realizar trabajos informales o incluso no realizar ningún tipo de trabajo productivo (que genere dinero, sea formal o informal), puede tener relación con el hecho de encargarse de la crianza de los hijos, el cuidado del hogar, el cuidado de familiares enfermos y/o el cuidado de adultos mayores (Guzmán \& Dalén, 2013).

De acuerdo con Corina (2005), las mujeres están siendo reclamadas desde la sociedad para aportar económicamente, asociado igualmente al incremento de parejas de doble ingreso (Aguirre \& Martínez, 2006), o al madresolismo; sin embargo, estas no se encuentran exentas de las demandas sociales de su rol clásico al interior del hogar, donde siguen siendo las principales encargadas (Ajenjo \& García, 2011). Según Medialdea (2016), comparadas con los hombres, las mujeres dedican el doble del tiempo a actividades de cuidado o trabajo reproductivo, así estén trabajando productivamente a la vez, dando lugar a la doble jornada femenina (Rodríguez, 2005; Guzmán \& Dalén. 2013). En algunos casos, ambas labores se hacen dedicando las horas de descanso y tiempo de ocio personal, llevando al deterioro de su calidad de vida (Floro, 1999, citado por Rodríguez, 2005; Cruz, Noriega \& Garduño, 2003), y evidenciando poca equidad respecto a la distribución del trabajo reproductivo entre los géneros (Gómez, 2002; Todaro, 2015).

El trabajo reproductivo se encuentra en el seno del sector informal (Chen, 2012), y a su vez el productivo en el marco del formal, donde por lo general el primero no implica pago y el segundo, sí (D’Angelo, 2011), aunque ciertamente pueden encontrarse trabajos reproductivos pagados, es decir, con características de productivo (Baca, 2015), y otros productivos no pagados, como el trabajo voluntario, que restaría a la naturaleza de productivo por el no pago. El trabajo reproductivo, de acuerdo con Benería (1981) y Torns y Carrasquer (1987) comprende las actividades destinadas a atender el cuidado del hogar y de la familia, no es remunerado (Benería, 1981; Torns \& Carrasquer, 1987; D’Angelo, 2011), es realizado en su gran mayoría por mujeres, es poco reconocido socialmente, no se considera un trabajo (Vega, 2007; Baca, 2015), y es transmitido de generación en generación (Triana, 
Ávila \& Malagón, 2010). De acuerdo con Castells (1997) y Vásquez, Cárcamo y Hernández (2012), lo anterior se relaciona con la atribución natural que se hace a las mujeres como poseedoras de características como la fertilidad, la delicadeza y la capacidad de cuidar a otros. Según Daros (2014), estas atribuciones a lo femenino históricamente contaron con valoraciones secundarias, comparadas con las atribuidas a los hombres con valoraciones de superioridad, a excepción de la maternidad desde el valor de la procreación.

Para Aguirre (2003) hay cuatro modalidades del trabajo reproductivo, el trabajo doméstico, el cuidado de familiares (aunque para Aguirre, 2007, esta es una labor diferente del trabajo reproductivo), el servicio a la comunidad, y un modo velado de trabajo productivo de subsistencia, donde se generan unos ingresos mínimos para el propio consumo, por supuesto en el marco de la informalidad.

De acuerdo con Dakduk (2010) y Larrañaga, Arregui y Arpal (2004) las mujeres presentan menos posibilidades de discusión respecto a la asignación de trabajo reproductivo en comparación con los hombres, pese a que su participación ha aumentado en generaciones recientes, sin que iguale la de las mujeres (Guzmán \& Dalén, 2013; Baca, 2015), lo que sigue representando para ellas sobrecarga (Herrera, 2000). Ruiz-Pérez, Plazaola-Castaño y Montero-Piñar (2011) confirmaron por su parte la existencia de inequidad de género respecto al cuidado informal, donde las mujeres cargan con tareas de cuidado más frecuentemente que los hombres, y con un mayor número de horas dedicadas a estas tareas. Según Álvarez y Gómez (2011), históricamente la relación laboral funcionó bajo las premisas de padre proveedor-madre cuidadora, en donde se trazó una división sexual del trabajo, y según Ruiz-Pérez, Plazaola-Castaño y Montero-Piñar (2011), estas situaciones terminan reflejándose en sobrecarga y la reducción de la calidad de vida influyendo en la aparición de distrés psicológico.

El ser cuidadora le implica a la mujer renunciar a compromisos u ofertas laborales (Dakduk, 2010), limitar la distribución de tiempo personal (Benavides, 2012), y depender económicamente de alguien. Entre parejas heterosexuales donde ambos realizan trabajo productivo, son las mujeres quienes tienden a ceder y ajustar sus proyectos laborales para responder a esta demanda; los hombres presentan más una ayuda o apoyo, cuando se trata de realización de actividades de tipo reproductivo, que de su repartición 
equitativa (Guzmán \& Dalén, 2013). En el hogar, puede ocurrir lo que Aguirre (2007) denomina el déficit del cuidado, donde la mujer que tiene trabajo productivo se encarga sola del trabajo reproductivo del hogar, contando con pobre o nula participación por parte de la pareja u otros integrantes de la familia. De esta manera, "el género es un elemento constitutivo de las relaciones desiguales de poder que se configuran en el mercado laboral..." (Guzmán \& Dalén, 2013, p.8).

Pese a lo anterior, se reconoce que existe cada vez una tendencia a pasar de nombrarlas como amas de casa a trabajadoras domésticas, como un modo de reconocerlo como actividad laboral, así no sea pagada, cuestión propia del sistema capitalista respecto al trabajo reproductivo (Blazsek \& Saenz, 2016), y que puede/debe implicar la participación de otros miembros de la familia, además de la mujer/madre del hogar (Lobera-Serrano \& García-Sainz, 2014).

En esta misma dirección, Agirre-Miguélez (2016) menciona que, respecto al trabajo reproductivo, los procesos de negociación de las parejas en la actualidad tienden a contar con posiciones más igualitarias en comparación con décadas pasadas, lo que en ocasiones causa tensión porque ya no se asume necesariamente como un asunto natural. Pese a lo anterior, de acuerdo con la Organización Internacional del Trabajo, las mujeres trabajan un mayor número de horas en actividades de cuidado y labores domésticas comparadas con los hombres tanto en países desarrollados como en vias de desarrollo. Así mismo, el tiempo laborado por las mujeres es mayor cuando se suma el trabajo productivo y el reproductivo; aun estando empleadas las mujeres tienden a asumir la mayor parte de las labores de cuidado y tareas domésticas no remuneradas.

Se espera que quien realice el trabajo reproductivo en casa, que por lo general es la mujer, lo realice con amor, razón por la cual se supone que no requiere ser pagado o compensado económicamente (Blazsek \& Saenz, 2016). Esta expectativa se relaciona con que el trabajo reproductivo trae consigo la realización de trabajo emocional (Hochschild, 1983). Para el autor, el trabajo emocional requiere que el individuo dentro de su trabajo, con ciertos parámetros o reglas conocidas como feeling rules, tenga las habilidades de inducir o suprimir emociones con el fin de mantener una apariencia externa determinada. Esto se da con el propósito de producir en los otros un estado mental apropiado o deseado según el contexto laboral. 
Salanova, Gracia y Peiró (1996) definen el constructo significado del trabajo, como un conjunto de valores y creencias hacia el trabajo que los individuos y grupos sociales van desarrollando antes y durante el proceso de socialización. En relación con los significados del trabajo, Neffa (2003) plantea que los conceptos y de definiciones básicas que las personas poseen alrededor del trabajo están enlazados en primer lugar, con el ejercicio efectivo de alguna actividad laboral expresada en la tendencia de alguna ocupación y, en segundo, con la voluntad de buscar alguna actividad laboral, por lo que es relevante investigar dichos significados según las ocupaciones actuales, o las de interés para la persona, o las modalidades de vinculación o contratación. De acuerdo con MOW International Research Team (1987), el significado del trabajo está compuesto por tres dimensiones: la centralidad, las normas sociales y los valores laborales.

La centralidad es entendida como una creencia, respecto al valor del trabajo en la vida de las personas; puede ser relativo o absoluto. Dicha centralidad se compone a su vez de dos aspectos fundamentales que varían según la importancia que tenga el trabajo para el individuo. El primer componente es el de creencia-valor, que radica en la identificación con el trabajo, resultado de un proceso de comparación entre el trabajo como actividad y las percepciones del self. El segundo componente es el de orientación-decisión que se encuentra basado en los intereses centrales vitales (central life interests), es decir, en la preferencia que el sujeto expresa por la realización de una determinada actividad (MOW International Research Team, 1987).

Las investigaciones realizadas por Dubin $(1956,1992)$ indican que el sujeto mismo es quien decide hacer de una actividad algo central para su vida; la elección está relacionada con las satisfacciones que obtiene el trabajador al realizar una actividad, razón por la cual decide si le emplea tiempo o no. Para Rokeach y Regan (1980), la centralidad se relaciona con las actitudes, encaminándolas hacia los valores, ya que para los autores se trata de un constructo que incluye componentes motivacionales, afectivos, cognitivos y a su vez conductuales. Por su parte Drenth (1991) identificó dos aspectos cruciales para definir centralidad, el primero es el concepto que cada individuo tiene de sí mismo en relación con su trabajo, el papel que este juega en su vida y qué tan comprometido se encuentra con el mismo. El segundo son las oportunidades que el individuo tiene para elegir las actividades de su trabajo. 
Respecto a la segunda dimensión del constructo significado del trabajo, llamada creencias normativas, o también conocidas como normas sociales, puede decirse que son razonamientos normativos que actúan como antecedentes de los principios y conductas sociales. En esta misma línea, Quintanilla y Wilperts (1991) plantean que las creencias son expectativas sociales frente a las cuales tanto el trabajo como las recompensas son juzgados, respecto a lo justas, equitativas y socialmente legítimas que puedan ser. Dentro de las creencias normativas, el MOW International Research Team (1987) esboza que existen dos categorías. La primera de ellas es la de deberes u obligaciones que, según Quintanilla y Wilperts (1991), son aquellas que hacen referencia a las normas que subyacen para todos los individuos en el contexto del trabajo, acerca de sus obligaciones hacia las organizaciones y la sociedad, es decir, al conjunto de responsabilidades que el individuo tiene en el momento de realizar su trabajo. La segunda categoría son los derechos laborales, normas que representan los derechos subyacentes de los individuos en el contexto laboral y las responsabilidades de la sociedad y las organizaciones hacia todos los trabajadores (Ruiz-Quintanilla \& Wilpert, 1991), más allá de las normas laborales legales de cada país.

Finalmente, la tercera dimensión del constructo significado del trabajo y según el MOW International Research Team (1987) son los resultados valorados o valores laborales, definidos como aquellas funciones que se perciben en el trabajo, que son de valor para el individuo; es decir, lo que el individuo espera que le aporte. Para Rokeach y Regan (1980), los valores son un constructo que se restringe a una clase especial de creencias perdurables en el tiempo, que varían en importancia y se encuentran ordenadas jerárquicamente, sobre determinadas metas y comportamientos que pueden ser de carácter personal o social, en comparación con otros que guían la selección de conductas y la evaluación de personas o situaciones.

Referente al concepto de valor que resulta imprescindible a la hora de referirse a la centralidad, Schwartz y Bilsky (1987) plantean que los valores son metas deseables que varían en importancia y guían los principios en la vida de las personas. Entonces podría decirse que la centralidad del trabajo, sea esta relativa o absoluta está directamente relacionada con los valores que son relevantes para la persona, incluso no solo con aquellos relativos al mundo del trabajo.

El significado del trabajo puede variar en función de si se realiza en el marco de la formalidad o la informalidad; de acuerdo con Dakduk, González 
y Montilla (2008) los trabajadores informales valoran más el pago, y los trabajadores formales, el aprendizaje y las condiciones de trabajo. Según Bendassolli y Borgues (2011), un trabajo será más significativo si permite nuevas posibilidades para aprender y actividades que tengan significación social, que ofrezcan oportunidades de expresión e identificación, mediante las buenas relaciones y autonomía. Veloz (2010) señala que en mujeres el trabajo tenderá a ser más significativo si estas, cuando están recién insertas en el mercado de trabajo, cuentan con pago y prestaciones sociales, motivándolas a seguir trabajando; por su parte Teixeira y Carvalho (2015) indican que el significado de trabajo en las mujeres se ve permeado por hechos que hayan marcado su trayectoria laboral.

En la misma dirección que Veloz (2010), Arce y Velarde (2001) concluyen que el significado del trabajo en mujeres se encuentra asociado con la necesidad de aumentar el ingreso, como una obligación moral y económica, frente a lo cual ellas asumen una actitud de conformismo y una aceptación impuesta marcada por las diferencias de género, aunque a su vez se evidencie realización personal por poder acceder a dinero fruto del trabajo. Long (2016) expresa que para analizar la manera como las mujeres se significan el trabajo, deben considerarse no solo aspectos relativos al género, sino también a la generación y a la cultura de la que hacen parte; incluso plantea que los significados se relacionan con el momento de desarrollo que tenga el país donde trabajen, y con las reformas laborales que se hayan dado durante los años de su ejercicio laboral.

De acuerdo con la revisión efectuada, los significados varían en función del trabajo realizado, sus condiciones y las construcciones simbólicas culturales que se han hecho en relación con el trabajo, en particular considerando la dicotomía productivo-reproductiva. Como presupuesto se consideró que la manera de significarse el trabajo entre las mujeres que realizan trabajo productivo, será diferente de aquellas con trabajo reproductivo. Así mismo se partió de considerar que es probable que las que desempeñan trabajo reproductivo, no lo califiquen como trabajo propiamente dicho.

\section{MÉTODO}

\subsection{Diseño}

El presente estudio se realizó bajo el paradigma cualitativo, definido por Denzin y Lincoln (2000) como una actividad que sitúa al observador en el mundo y consiste en una serie de prácticas interpretativas que hacen el 
mundo visible. Tuvo un diseño de carácter fenomenológico que según Salgado (2007), se enfoca en las experiencias individuales subjetivas de los participantes; este tipo de diseño responde a cuál es el significado, estructura y esencia de una experiencia vivida por una persona, grupo o comunidad respecto de un fenómeno, razón por la cual permite acceder a información detallada, y suscitar en las participantes reflexiones e información que con perspectivas de naturaleza nomotética no sería posible.

\subsection{Participantes}

12 mujeres de la ciudad de Cali, Colombia, donde seis de ellas contaban con trabajo productivo (con modalidad de empleo de tiempo completo, algunas ejerciendo su profesión y otras en oficios según se muestra en la Tabla 1), y seis con trabajo reproductivo. El primer criterio de inclusión para las mujeres con trabajo reproductivo fue que solo se dedicaran a este tipo de trabajo, que tuvieran hijos, pareja y, que anteriormente hubieran tenido trabajo productivo mínimo durante un año. En el caso de las mujeres con trabajo productivo, los criterios de inclusión fueron encontrarse en condición de empleo y recibir remuneración, tener hijos, pareja y, anteriormente haberse dedicado durante algún tiempo al trabajo reproductivo. Lo anterior para que tanto unas participantes como las otras pudieran hacer el contraste entre su condición laboral actual en relación con vivencias previas realizando el otro tipo de trabajo. En la Tabla 1 se encuentran los datos sociodemográficos de las participantes.

Las participantes fueron contactadas mediante la técnica de bola de nieve, definida por Cohen y Manion (1990), como un procedimiento de muestreo que supone que el investigador identifique a un pequeño grupo de individuos que tienen las características que se requieren según los criterios de inclusión enunciados. A medida que se iban contactando las entrevistadas, estas a su vez iban refiriendo conocidas que estuvieran en condiciones laborales similares, aspecto que facilita el establecimiento de una relación de confianza con los nuevos participantes, y también permite acceder a personas difíciles de identificar. Por último, el investigador tiene menos problemas para especificar las características que desea de los nuevos participantes (Salamanca \& Crespo, 2007). Se consideraron 12 participantes basados en el criterio de saturación entendido, según Morse (1995), como el punto en el cual se ha escuchado cierta diversidad de ideas y que con cada entrevista adicional no aparezcan otros elementos, además de contar con información suficiente y de calidad para realizar un análisis adecuado que responda al problema de investigación. 
Tabla 1.

Datos sociodemográficos de las participantes

\begin{tabular}{|c|c|c|c|c|c|c|}
\hline No. & EDAD & ESTRATO & NIVEL EDUCATIVO & $\begin{array}{l}\text { TIEMPO } \\
\text { EN ÚLTIMA } \\
\text { ACTIVIDAD }\end{array}$ & $\begin{array}{c}\text { ESTADO } \\
\text { CIVIL }\end{array}$ & $\begin{array}{l}\text { NÚMERO } \\
\text { DE HIJOS }\end{array}$ \\
\hline \multicolumn{7}{|c|}{ MUJERES CON TRABAJO REPRODUCTIVO } \\
\hline 1 & 35 & 3 & Administradora de empresas & 15 años & Casada & 1 \\
\hline 2 & 40 & 4 & Bachiller & 12 años & Casada & 2 \\
\hline 3 & 34 & 3 & Bachiller & 10 años & Casada & 1 \\
\hline 4 & 38 & 3 & Bachiller & 20 años & Casada & 1 \\
\hline 5 & 37 & 3 & Bachiller & 14 años & Unión libre & 1 \\
\hline 6 & 40 & 3 & Bachiller & 14 años & Casada & 2 \\
\hline \multicolumn{7}{|c|}{ MUJERES CON TRABAJO PRODUCTIVO (EMPLEO DE TIEMPO COMPLETO) } \\
\hline 1 & 36 & 2 & Enfermera (en su profesión) & 12 años & Unión libre & 4 \\
\hline 2 & 40 & 5 & Contadora (en su profesión) & 18 años & Unión libre & 2 \\
\hline 3 & 35 & 3 & Bachiller (niñera) & 16 años & Unión libre & 1 \\
\hline 4 & 39 & 2 & Bachiller (operaria de fábrica) & 15 años & Unión libre & 3 \\
\hline 5 & 40 & 4 & $\begin{array}{l}\text { Licenciada en Educación Preescolar y Administra- } \\
\text { dora de Empresas (Auxiliar adm.) }\end{array}$ & 22 años & Unión libre & 2 \\
\hline 6 & 39 & 3 & Enfermera (Jefe de enfermeras) & 20 años & Casada & 2 \\
\hline
\end{tabular}

\subsection{Instrumentos}

\subsubsection{Entrevista semiestructurada}

De acuerdo con Corbetta (2007), en esta entrevista el entrevistador cuenta con un guion flexible sobre el que puede decidir libremente respecto al orden y el modo de formulación de las preguntas.

Teniendo en cuenta que la entrevista varía según las formas que se emplean para el acercamiento y la situación en la que se desarrolle, la entrevista realizada a las mujeres fue de tipo semi-estructurada, en la cual se planteó 
una guía o pauta de entrevista donde se indagó por tres temáticas centrales: significados de trabajo (centralidad, normas sociales y resultados valorados), tipo de trabajo y trayectorias laborales. La primera, alude a los valores y creencias respecto al trabajo que las mujeres desarrollan antes y durante el proceso de socialización; la segunda, a la historia laboral tanto de la mujer como de su familia que incluye pasado, presente y futuro, y finalmente tipo de trabajo, en este caso trabajo reproductivo y productivo.

Las preguntas incluidas en dicha entrevista, fueron formuladas a partir del planteamiento de categorías, subcategorías e indicadores (ver Tabla 2), lo anterior para garantizar que todas las preguntas guías fueran pertinentes y permitieran la obtención de información. Así mismo se realizó un estudio piloto, en el cual fueron entrevistadas tres mujeres, dos de ellas con trabajo reproductivo y una con trabajo productivo. A partir de esto se pudo evidenciar qué preguntas de la entrevista debían ser reformuladas y así mismo la pertinencia del instrumento de recolección.

En paralelo a las entrevistas piloto, se realizó una validación por tres jueces expertos, quienes dieron retroalimentación acerca de los cambios necesarios posteriores a la prueba piloto, con el fin de que la aplicación fuera más acertada y que a su vez respondieran a los objetivos de la investigación. Los perfiles de los jueces fueron una Psicóloga y Magíster en Psicología Cultural, experta en Psicología de Familia, en segundo lugar, otra Psicóloga y Magíster en Familia con experiencia en trabajo con mujeres en situaciones de enfermedad crónica y finalmente, una Antropóloga, Magíster en Lingüística y especialista en Administración Pública, experta en temas de género. A partir de la retroalimentación se cambiaron algunas preguntas de tal manera que fueran más pertinentes para la obtención de información, cabe resaltar que se empleó una guía de preguntas sin embargo, las investigadoras ahondaban o cuestionaban aspectos que consideraban de relevancia dentro de la narración de la persona aunque no estuvieran incluidas en la guía.

La triangulación de investigadoras se realizó en la medida en que, en las 12 entrevistas realizadas a las participantes, mínimamente dos de las tres investigadoras estuvieron presentes con el fin de posibilitar la confrontación de diferentes percepciones para la interpretación de los resultados. El tiempo promedio de duración de las entrevistas fue de 50 minutos. 


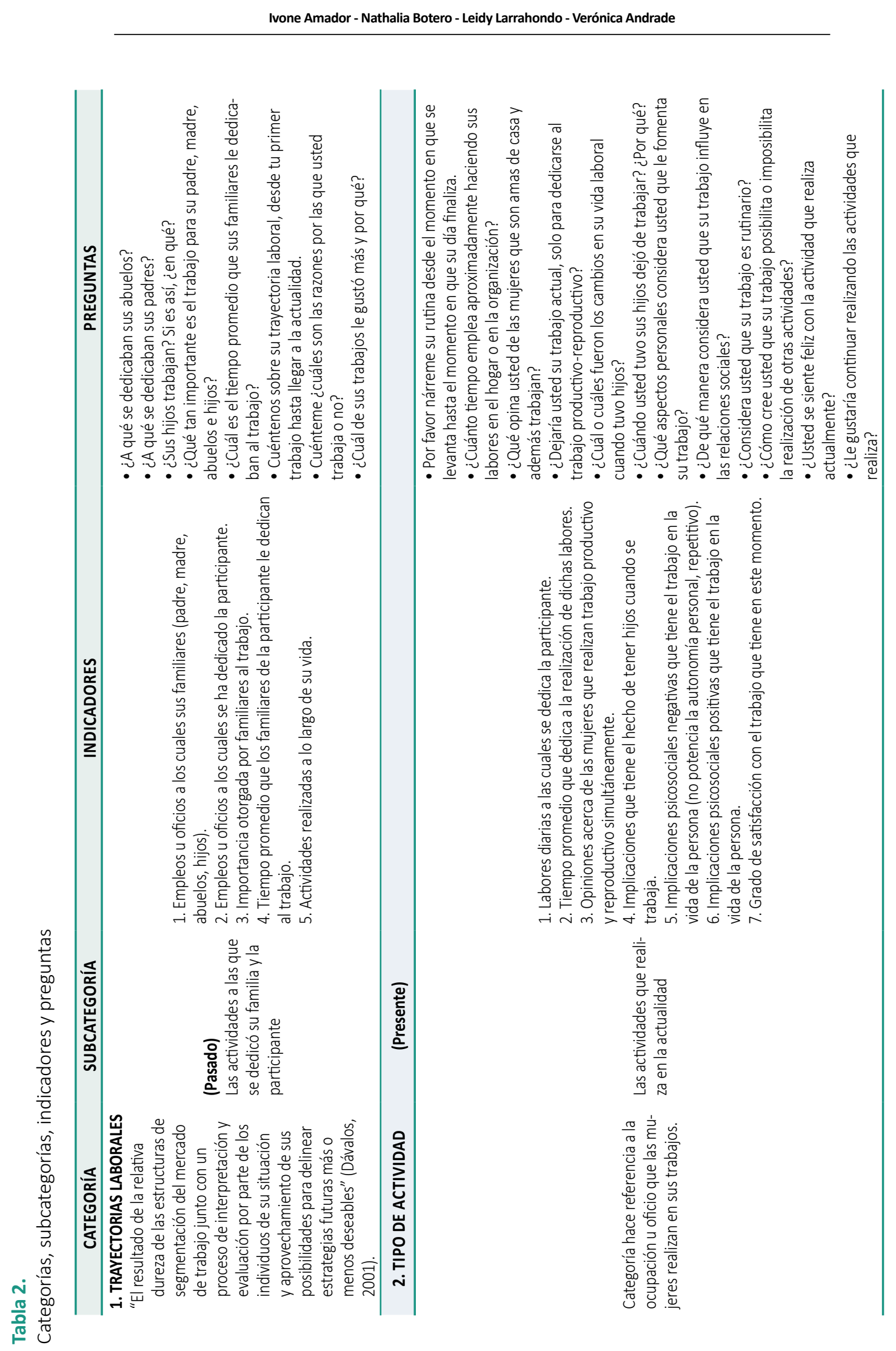




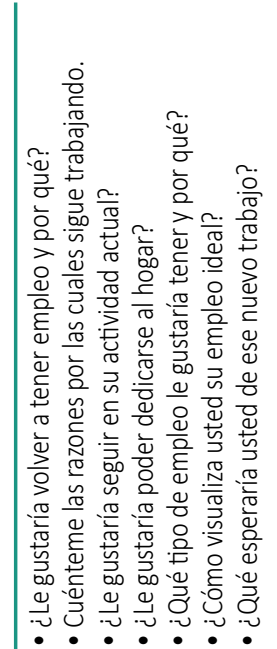

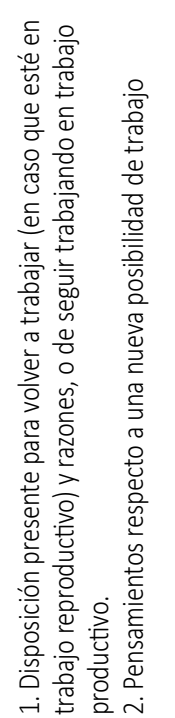
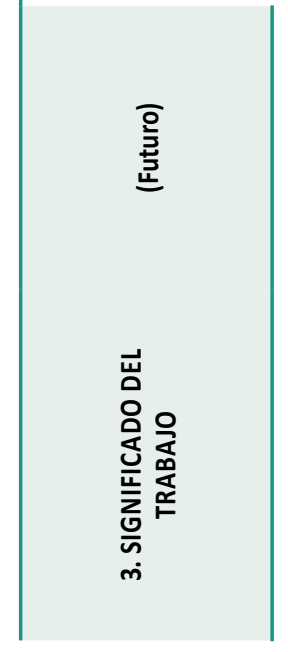
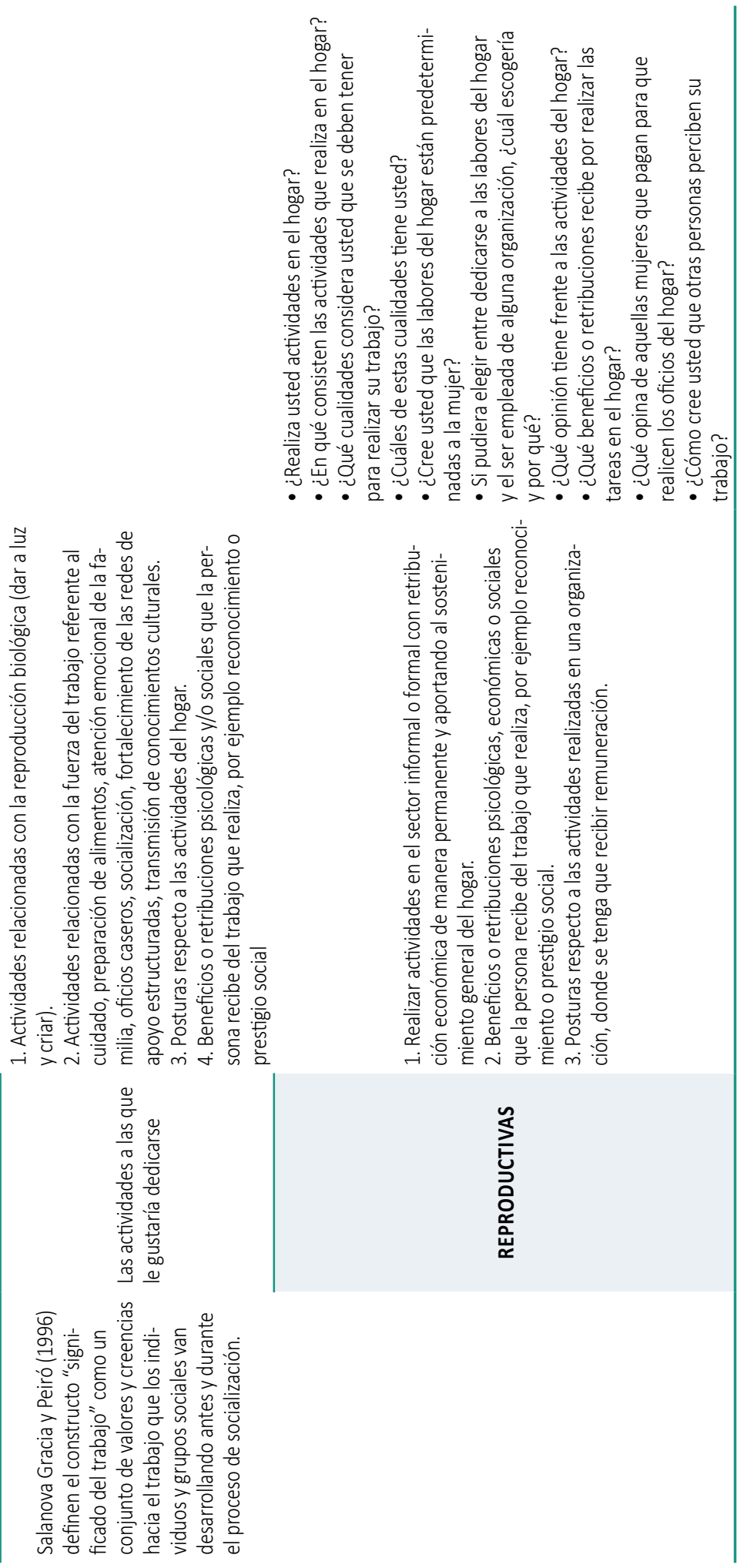


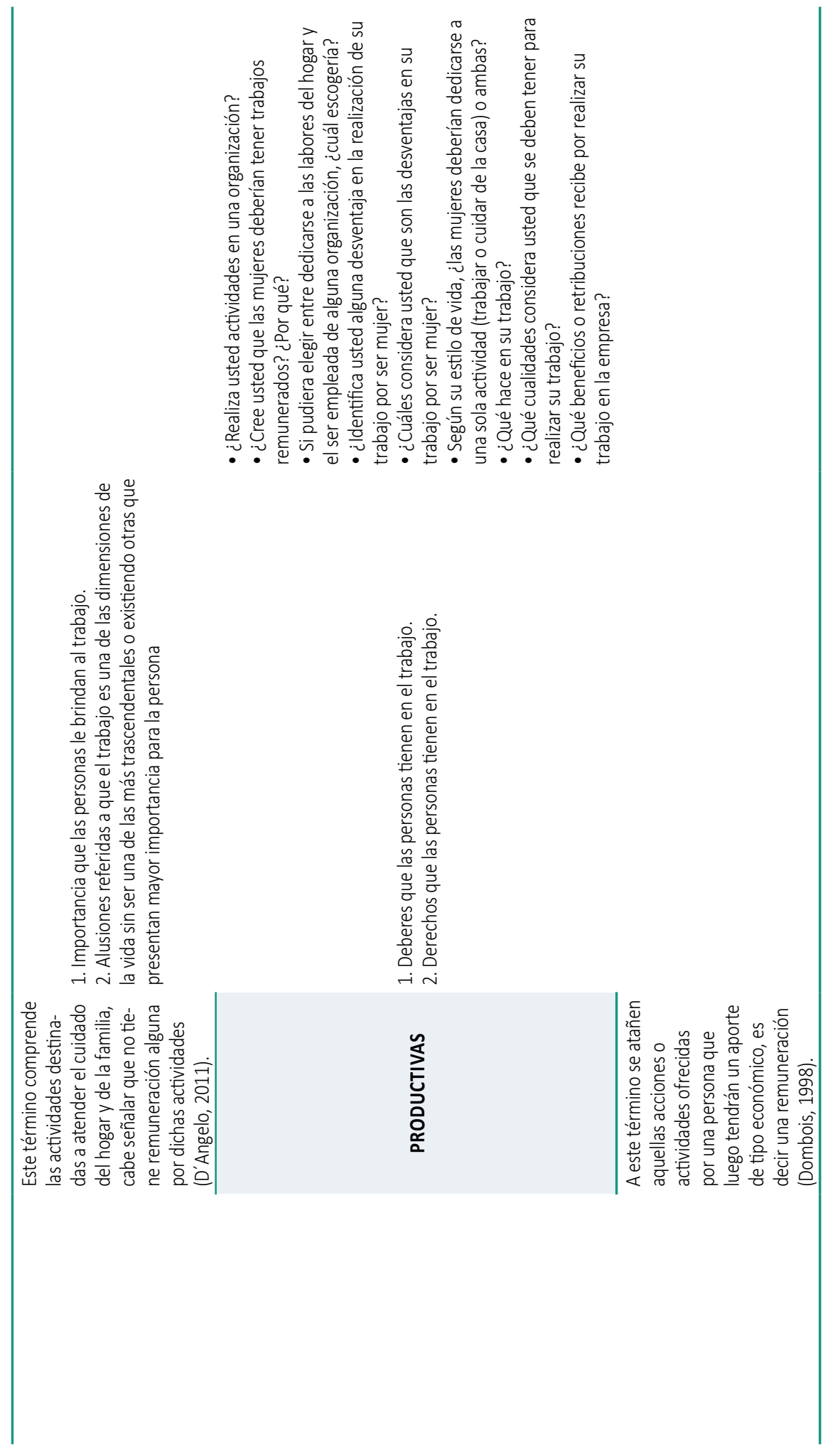




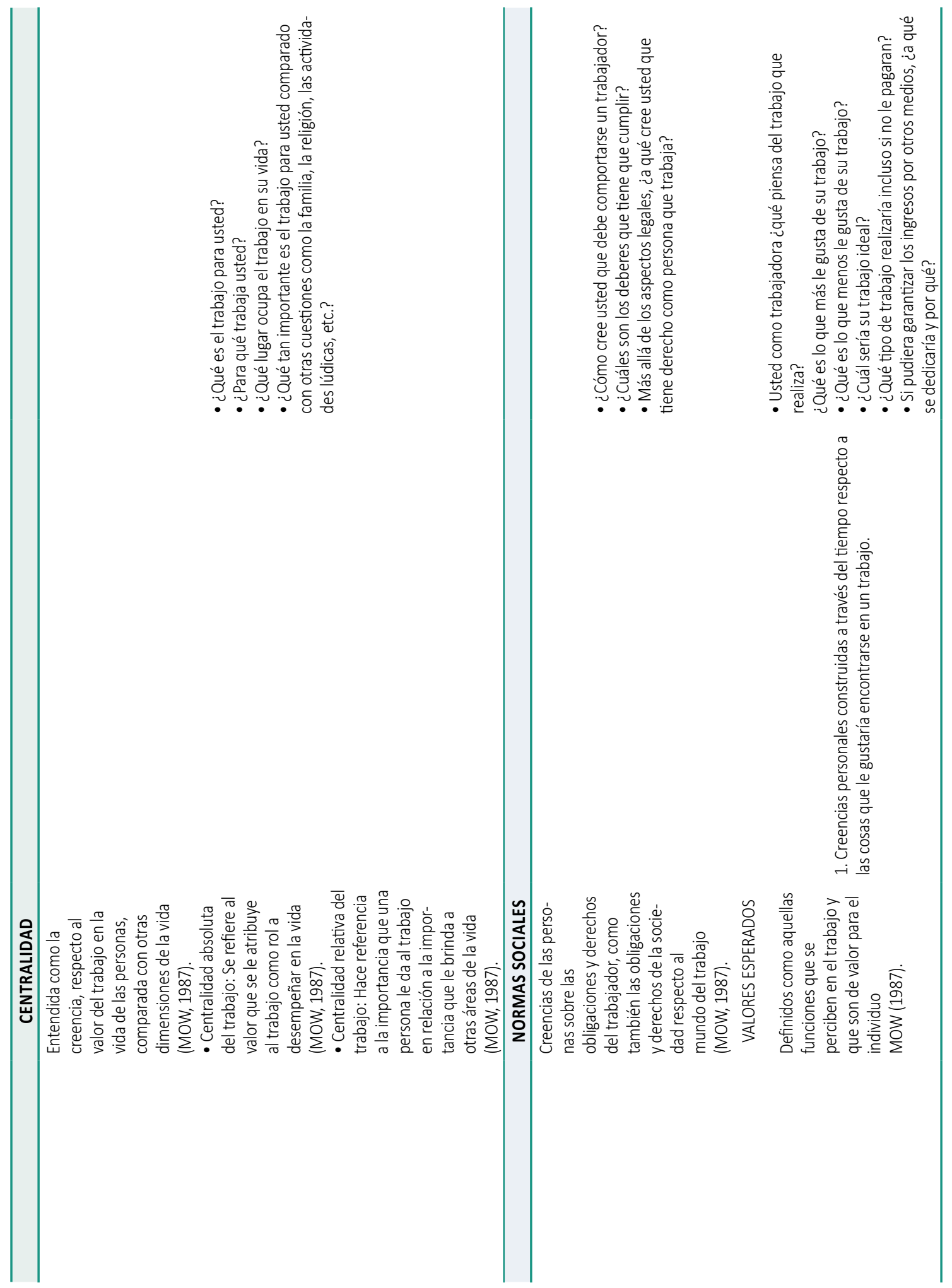




\subsubsection{Técnicas de análisis}

Se usaron la Técnica de Análisis de Contenido (Bardin, 2002) y la Técnica de Líneas Narrativas (Spink, 2013). La primera hace referencia a el conjunto de técnicas de análisis de las comunicaciones tendentes a obtener indicadores (cuantitativos o no) por procedimientos sistemáticos y objetivos de descripción del contenido de los mensajes permitiendo la inferencia de conocimientos relativos a las condiciones de producción/recepción (contexto social) de estos mensajes (Bardin, 2002). Para el presente artículo se trabajó con la regla de numeración presencia, y con la unidad de análisis tema; para el uso del análisis de contenido se consideró el Atlas-ti (versión 6.0) para facilitar el procesamiento de la información.

Al respecto de la unidad de registro tema, fue analizada desde la noción de categoría que para el presente caso fueron el significado del trabajo, tipo de actividad realizada, y trayectorias laborales. Sobre significado del trabajo se consideraron las dimensiones que reporta la literatura en relación con el constructo (centralidad, normas sociales y valores laborales); la categoría tipo de actividad se tuvo en cuenta porque partió del supuesto que el tipo de trabajo realizado (productivo o reproductivo) condiciona la manera de significarse el trabajo, por lo que fue central abordarla. Finalmente la categoría trayectorias laborales, hizo referencia al recorrido que tuvieran las participantes, en la medida que retomarlo les permitía tener reflexiones en perspectiva de su presente en relación con el pasado, y con el futuro, aspecto que se amplió a través del uso de la técnica de análisis líneas narrativas. A las categorías mencionadas se le agregaron subcategorías e indicadores que permitieron recoger la información más completa y así brindar mejor análisis.

Así mismo se usó la técnica líneas narrativas (Spink, 2013), considerada como una valiosa herramienta que permite sintetizar los contenidos de las historias contadas en la entrevista en orden cronológico, que en este caso fue el Antes, el Presente y el Futuro, y permite identificar elementos que no fueron visibles inicialmente durante la realización de la entrevista. Cabe señalar que los hechos durante la entrevista no se mencionan de manera organizada según van ocurriendo, por lo cual se pueden reorganizar con el fin de favorecer inteligibilidad de los datos para encontrar coherencia y sentido a la narración de las mujeres y así comprender o analizar su significado. 


\subsection{Consideraciones éticas}

Todas las participantes conocieron, previa a su realización, los objetivos de la entrevista y el uso que se haría de su información. Se retomaron todas las consideraciones indicadas por la legislación colombiana correspondiente sobre investigaciones con seres humanos (Resolución 8430, Ministerio de Salud, 1993; Ley 1090, República de Colombia, 2006). Previamente a la entrevista cada una leyó y firmo el consentimiento informado respectivo. Las entrevistas contaron con grabación de voz autorizada por las participantes.

\subsubsection{Recolección y análisis de la información}

una vez se realizó la firma del consentimiento informado se realizaron las entrevistas Semi-Estructuradas a las participantes, donde se indagó acerca del significado que ellas le dan al trabajo, las dimensiones del significado del trabajo, la trayectoria laboral y la caracterización de sus tipos de trabajo. Posteriormente, se transcribieron las entrevistas. Posteriormente se realizó el análisis de la información con base en los datos arrojados en los resultados y se contrastó con la teoría.

\subsection{Análisis de datos}

Todas las entrevistas fueron transcritas usando sistema Jefferson (Bassi, 2015), y se procedió a analizarlas con base en los indicadores mostrados en la Tabla 2. Se realizaron dos tipos de procesamiento, uno de análisis de contenido, y otro de líneas narrativas. En el primero, se establecieron frecuencias de los indicadores, y respecto a las líneas, se identificaron líneas narrativas comunes a las 12 participantes en los tiempos pasado, presente, $y$ futuro. En las codificaciones y análisis participaron todas las investigadoras.

\subsection{Conflicto de interés}

No se reporta conflicto de intereses en la investigación; no se recibieron dineros de ninguna fuente en particular para financiar este estudio que pueda poner en consideración los resultados presentados, ni tampoco existía ningún grado de familiaridad con las participantes.

\section{RESULTADOS}

\subsection{Resultados de las líneas narrativas}

Se identificaron seis líneas narrativas en las entrevistas analizadas considerando tres momentos cronológicos, el Antes, el Ahora y el Futuro. Las líneas 
se infieren al leer en repetidas ocasiones la información y hallar elementos comunes entre las 12 participantes. Estas líneas fueron: La interacción con los hijos, el dinero/remuneración, las actividades en el hogar, las responsabilidades, las relaciones de pareja, y la trayectoria laboral. Las líneas narrativas se analizaron por presencia, es decir, a través de la mención de temas, por lo que no se expone su frecuencia, a diferencia del análisis de contenido.

\subsubsection{Interacción con los hijos}

En esta línea, mujeres con trabajo reproductivo (MTR) y mujeres con trabajo productivo (MTP) en su mayoría manifiestan el disfrute de estar con ellos, dedican su tiempo para apoyarlos en la educación, expresan ser constantes y se muestran felices con lo realizado. Las MTR señalan que antes de tener sus hijos, trabajaban en actividades productivas, dejaron de hacerlo para dedicarse completamente a las labores del hogar. En la actualidad, expresan que están pendientes de sus hijos todo el día, almuerzan juntos, brindan apoyo en lo académico y además atienden sus necesidades. Por su parte, las MTP se organizan para dedicar el tiempo necesario a sus hijos según disponibilidad de horarios por el trabajo.

“tengo un hijo que está en la preadolescencia y es la edad más difícil para que yo lo deje solo (...) mi hijo menor me necesita (...) apoyar a mis hijos en sus procesos de maduración". (MTR 02)

"el cambio fue los tres meses que laboralmente o reglamentarios le dan a uno, pero que me haya cambiado la vida laboral no... yo tuve mi niño y a los mesecitos a trabajar se dijo". (MTP 03)

\subsubsection{Dinero/Remuneración}

En esta línea, las MTR señalan que cuando tenían trabajos remunerados existía más independencia; las MTP mencionan que tienen independencia y reciben remuneración para costear sus estudios, ayudar a sus familiares, adquirir vivienda y generar ingresos en el hogar. Las MTR en la actualidad no reciben pago en dinero por lo realizado en el hogar, sin embargo dos de las seis tienen ingresos por medio de otras actividades, como vender productos capilares o por catálogos. En cuanto a las MTP, reciben remuneración para poder aportar y/o colaborar en el hogar. En el futuro, tanto MTR como MTP anhelan un trabajo donde la remuneración sea buena y mayor que en la actualidad, además de tener la posibilidad de compartir más tiempo con sus familias mediante la flexibilidad en los horarios. 
"cuando trabajaba tenía independencia económica y podía comprar mis cosas (...) aunque tenía del apoyo de mi esposo, me quedaba el dinero para mí solita". (MTR 01)

Entre las cuestiones que valora de su trabajo:

"el pago que yo recibo, lo que pagan por lo que hago (...) en la casa tenemos bastante que hacer, pero no entra ningún ingreso (...) dejamos a veces de desatender nuestro hogar...igual tenemos que recibir un ingreso, que tal yo trabajando aquí y que no me pagaran". (MTP 04)

\subsubsection{Actividades en el hogar}

En esta línea, tanto MTR como MTP coinciden en organizar su tiempo para realizar las tareas en el hogar. En cuanto al futuro, no es una opción para las MTP dedicarse solo a las actividades en el hogar, por lo que esperan seguir teniendo trabajos productivos.

\subsubsection{Responsabilidades}

En esta línea, MTR y MTP coinciden en velar porque todo en la casa marche bien y realizar los quehaceres del hogar; sin embargo las MTP expresan tener responsabilidades en el lugar de trabajo que implica acomodarse a los horarios para poder cumplir con la doble jornada.

"cuando llego de trabajar hago almuerzo, hago el oficio, barro, trapeo, lavo, hago la comida...". (MTP 06)

\subsubsection{Relaciones de pareja}

En esta línea se encontró que ocho de las doce participantes coinciden en expresar que comparten en alguna medida las labores del hogar con sus parejas, con tendencia a que ellas asuman más responsabilidades y además reciben apoyo económico. Cabe señalar que la mayoría de las participantes expresan que los aportes económicos funcionan 70/30 donde su pareja es quien aporta el mayor porcentaje, particularmente en el caso de las MTP.

"...el hombre no, el hombre es fresco, pero como ellos no están en esa función, ellos no están pendiente de que el niño hay que cambiarlo, el panal, que al niño hay que hervirle los teteros, que al niño hay que hervirle el agua, ellos no están en eso". (MTR 03) 
"mi esposito no me ayuda para nada, entonces todo me toca a mí solita". (MTP 05)

\subsubsection{Trayectorias laborales}

En esta línea, las MTR expresaron haber tenido empleos remunerados estables hasta el momento en que tuvieron sus hijos, lo cual fue un factor determinante para dedicarse a las labores del hogar. En cuanto a las MTP, el hecho de tener hijos les exigió tener un empleo remunerado para suplir necesidades. Las MTR manifiestan que a futuro les gustaría conseguir un empleo cuya remuneración esté acorde con las labores a ejercer, además que haya tiempo para velar por el cuidado de la casa, que implica la crianza de sus hijos y el oficio. En cuanto a las MTP quisieran seguir en esta actividad, y anhelan otro lugar de trabajo donde respeten sus derechos, valoren su desempeño, tengan mayor remuneración o bien, trabajos independientes en los cuales haya más tiempo para compartir con la familia.

"Trabajo en el hogar por mis hijos, por generar en ellos valores".

(MTR 06)

"Al respecto del futuro quisiera un trabajo que tenga mejores beneficios, que se preocupen por el trabajador, que uno tenga como esas cosas de ascender, de no quedarse siempre en lo mismo, donde de pronto el trato pueda ser bueno". (MTP 05)

\subsection{Resultados de la técnica de análisis de contenido}

Se encontró que los significados del trabajo en el caso de las MTP incluyen desarrollar habilidades, aportar económicamente al hogar, ejercer su profesión, construir relaciones nuevas, poder satisfacer sus gustos, proyectos de vida definidos, potencializar habilidades en el cargo, abrirse a nuevas experiencias, aportes intelectuales en el trabajo y satisfacer necesidades.

"trabajo para sostenerme económicamente, sostener a mi hijo y ayudar a mi madre, mi pareja me colabora alguito, no es que sea mucho... pero me toca, porque cuando peleamos, él no responde y se desaparece". (MTP 03)

Entre las MTR se encontró que los significados giran alrededor de mantener el hogar en buenas condiciones, atender a su pareja, determinar normas dentro del hogar, construir vínculos familiares estables, apoyar la educación de sus hijos y generar ingresos extras para apoyar económicamente en el hogar. 


\section{"Tener mi casa limpia, sentirme bien, organizar, tener limpio, si está mi familia aquí, atenderlos, que se sientan bien, esas actividades me gustan". (MTR 04)}

Referente a la dimensión de centralidad del trabajo (que es una de las dimensiones del Significado del trabajo) en la vida de las participantes, se evidenció una mayor alusión o importancia por parte de las MTP, puesto que afirmaban que jamás se percibirían como personas desempleadas y que constantemente están en la búsqueda de oportunidades laborales. El trabajo en varias de ellas representa la fuente más importante de satisfacción de necesidades, y prefieren interrumpir sus actividades o relaciones sociales para invertir tiempo en sus trabajos; para las demás MTP es tan central como otras dimensiones de la vida. Las MTR, por su parte, expresan el trabajo como una dimensión de sus vidas, no de categoría prioritaria, pero sí como un aspecto importante a través del cual se puede ayudar al núcleo familiar ya que lo piensan desde una perspectiva productiva; lo que realizan diariamente no lo clasifican como trabajo.

Refiriéndose al trabajo productivo

“No, no lo dejaría, para hacer las cosas de la casa, no, no, no, ni loca pues". (MTP 03)

Respondiendo a si conseguiría trabajo productivo

"En el momento no, porque tengo un hijo que está en la preadolescencia y pienso, que esa es la edad más difícil para uno dejarlos solos". (MTR 02)

Respecto a las normas sociales las mujeres de las dos modalidades, manifiestan con facilidad los derechos y deberes que deben cumplir en sus respectivos trabajos. No obstante cabe resaltar algunas diferencias en cuanto a los derechos reconocidos, ya que para las MTR los derechos están más ligados al reconocimiento de su trabajo y a su valoración, como también al apoyo que le den los miembros de su familia con el trabajo reproductivo. Las MTP plantean sus derechos desde el marco legal y de lo que merecen o requieren de la entidad para la que trabajan. Así mismo el aspecto monetario también fue resaltado por ellas, quienes desearían un aumento salarial y recibir buenos tratos por parte de las personas con las que trabajen, así como contar con un trabajo donde ellas sean quienes manden o dirijan, demostrando su interés en actuar frente a otras personas en situación de jefes. 
"Que me pagaran lo que me merezco con todo lo legal y lo extra legal, tooodo pues y ya" (MTP 02).

Respecto a la dimensión valores laborales las MTR expresaron aspectos de tipo emocional, referente a que la labor que desempeñan beneficia a los miembros de su familia donde su recompensa es el afecto que reciben, y el reconocimiento de aquellos con palabras de admiración, felicitación por alguna tarea efectuada, entre otras; sin embargo, también resaltaron la importancia de recibir ganancias monetarias por lo que consideran que el pago de un salario ayudaría a compensar muchas de las necesidades que surgen en el día a día. Las MTP señalan la necesidad de que las mujeres se vinculen a la vida laboral para convertirse en mujeres independientes, que también aporten al hogar y a su sostenimiento, sin miedo a un posible abandono de sus parejas, lo cual incluiría inestabilidad de tipo económico en caso de que ocurriera si se dedican exclusivamente a actividades reproductivas.

"Me gustaría tener un trabajo en el que gane dinero, para tener más solvencia económica, tener tiempo para mi familia (...) trabajaría en una organización, dependiendo de la remuneración que uno tenga, en dinero en ese trabajo y el tiempo, porque hay trabajos que demandan mucho tiempo y no puede estar uno con la familia en la casa". (MTR 05)

De acuerdo con el tema de deberes laborales, las participantes reconocen, en cierta medida, cuáles deben cumplir en el lugar de trabajo; en el caso de las MTP, se hace un reconocimiento frente a características de tipo emocional y físico, de cómo se esperaría que fuesen para cubrir en su totalidad las que se requieran. Frente a las actividades que deban realizar en su lugar de trabajo, las MTP destacan que estas son asumidas una a una, siempre indicando que pese a la duración de su jornada laboral quieren hacer notoria su participación o contacto con la familia.

Para el caso de las MTR, consideran como deberes todas las actividades que deben ejecutar en su jornada diaria, y, cómo los miembros de su familia dependen o depositan trabajos que, según indican, solo la madre podría hacer bien, como por ejemplo: planchar para su pareja la camisa para una reunión importante, atender al bebé de la familia todas las veces que lo requiera, cuidar a los miembros de su familia cuando enfermen, mantener limpia la casa, y preparar los alimentos a horas específicas durante el día. Estos aspectos o tareas mencionados están en función de lo que deben hacer en su trabajo y de personas que esperan que sean bien ejecutados. Tanto las 
MTR como las MTP mencionaron que perciben inequidad respecto a la repartición de las tareas del hogar con su pareja, y en general de los miembros de la familia.

"Como vivimos en un país que es machista, entonces, eso básicamente le corresponde a la mujer -refiriéndose a las labores del hogar-, porque si un hombre hace esas actividades está perdiendo, pues, como puntos de ser hombre". (MTR 02)

“...Aquí en Colombia, se es machista, la mujer hace... es la que lava, la que todo (...) pero la cultura la debe formar la mujer, no el hombre, mira el bebé nace sin ningún Resabio" (...) él graba todo lo que ve, uno como mamá le mete huevonadas (...) Es un cosa impresionante, si el hombre lava entonces es marica". (MTR 03)

"Los hombres aquí en Colombia, lastimosamente, les enseñan en casa que ellos miran mientras la mujer trabaja, hablando del hogar pues". (MTR 06)

En la tabla 3 se evidencian los resultados por frecuencia de la técnica Análisis de contenido.

Tabla 3.

Resultados derivados de la técnica de análisis de contenido-Frecuencia

\begin{tabular}{|c|c|c|c|c|c|c|c|c|c|c|c|c|c|c|c|}
\hline \multirow{4}{*}{ 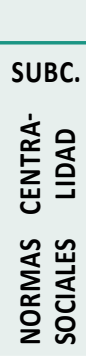 } & \multicolumn{15}{|c|}{ REPRODUCTIVO } \\
\hline & INDICADOR & 1 & 2 & 3 & 4 & 5 & 6 & TOTAL & 1 & 2 & 3 & 4 & 5 & 6 & TOTAL \\
\hline & $\begin{array}{l}\text { Grado de importancia que las personas le } \\
\text { brindan al trabajo }\end{array}$ & 4 & 4 & 4 & 4 & 1 & 1 & 18 & 2 & 5 & 3 & 2 & 4 & 3 & 19 \\
\hline & $\begin{array}{l}\text { Alusiones referidas a que el trabajo es una } \\
\text { de las dimensiones de la vida }\end{array}$ & 5 & 2 & 1 & 2 & 11 & 0 & 21 & 0 & 7 & 3 & 0 & 2 & 1 & 13 \\
\hline & $\begin{array}{l}\text { Deberes que las personas tienen en el } \\
\text { trabajo }\end{array}$ & 3 & 7 & 12 & 1 & 2 & 6 & 31 & 4 & 11 & 9 & 5 & 4 & 3 & 36 \\
\hline & $\begin{array}{l}\text { Derechos que las personas tienen en el } \\
\text { trabajo }\end{array}$ & 2 & 3 & 8 & 1 & 1 & 4 & 18 & 1 & 5 & 4 & 5 & 2 & 2 & 19 \\
\hline 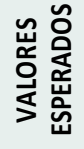 & $\begin{array}{l}\text { Creencias personales construidas a través } \\
\text { del tiempo }\end{array}$ & 6 & 2 & 8 & 2 & 10 & 1 & 29 & 4 & 3 & 3 & 5 & 4 & 4 & 23 \\
\hline 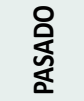 & $\begin{array}{l}\text { Empleos u oficios a los cuales sus familiares } \\
\text { se dedicaban (Padre, madres, abuelos, hijos) }\end{array}$ & 2 & 6 & 7 & 3 & 2 & 4 & 24 & 0 & 9 & 5 & 3 & 3 & 2 & 22 \\
\hline & $\begin{array}{l}\text { Empleos u oficios a los cuales se ha dedica- } \\
\text { do la participante }\end{array}$ & 9 & 10 & 6 & 4 & 5 & 8 & 42 & 6 & 16 & 18 & 4 & 5 & 4 & 53 \\
\hline & $\begin{array}{l}\text { Importancia otorgada por familiares al } \\
\text { trabajo }\end{array}$ & 1 & 2 & 1 & 1 & 1 & 3 & 9 & 0 & 4 & 5 & 1 & 1 & 1 & 12 \\
\hline
\end{tabular}




\begin{tabular}{|c|c|c|c|c|c|c|c|c|c|c|c|c|c|c|c|}
\hline \multirow[b]{2}{*}{ SUBC. } & \multicolumn{15}{|c|}{ REPRODUCTIVO } \\
\hline & INDICADOR & 1 & 2 & 3 & 4 & 5 & 6 & TOTAL & 1 & 2 & 3 & 4 & 5 & 6 & TOTAL \\
\hline \multirow{8}{*}{ 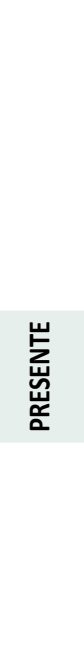 } & $\begin{array}{l}\text { Tiempo promedio que los familiares de la } \\
\text { participante le dedican al trabajo }\end{array}$ & 2 & 2 & 2 & 1 & 1 & 2 & 10 & 0 & 2 & 2 & 1 & 1 & 1 & 7 \\
\hline & $\begin{array}{l}\text { Tiempo promedio que dedica la participante } \\
\text { a dichas labores }\end{array}$ & 3 & 2 & 5 & 2 & 2 & 2 & 16 & 2 & 2 & 2 & 1 & 1 & 1 & 9 \\
\hline & $\begin{array}{l}\text { Opiniones acerca de las mujeres que reali- } \\
\text { zan trabajo productivo y reproductivo }\end{array}$ & 3 & 2 & 4 & 2 & 1 & 3 & 15 & 1 & 3 & 3 & 1 & 2 & 1 & 11 \\
\hline & $\begin{array}{l}\text { Actividades diarias a las cuales se dedica la } \\
\text { participante }\end{array}$ & 3 & 7 & 12 & 4 & 11 & 13 & 50 & 2 & 19 & 22 & 2 & 7 & 4 & 56 \\
\hline & $\begin{array}{l}\text { Implicaciones que tiene el hecho de tener } \\
\text { hijos cuando se trabaja }\end{array}$ & & & & & & & & & & & & & & \\
\hline & $\begin{array}{l}\text { Implicaciones psicosociales negativas que } \\
\text { tiene el trabajo en la vida de la persona }\end{array}$ & & & & & & & & & & & & & & \\
\hline & $\begin{array}{l}\text { Implicaciones psicosociales positivas que } \\
\text { tiene el trabajo en la vida de la persona }\end{array}$ & & & & & & & & & & & & & & \\
\hline & $\begin{array}{l}\text { Grado de satisfacción con el trabajo que } \\
\text { tiene en este momento }\end{array}$ & & & & & & & & & & & & & & \\
\hline \multirow[t]{2}{*}{ 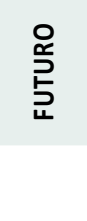 } & $\begin{array}{l}\text { Disposición presente para volver a trabajar } \\
\text { (en caso que esté en trabajo reproductivo) } \\
\text { y razones, o de seguir trabajando en trabajo } \\
\text { productivo }\end{array}$ & & & & & & & & & & & & & & \\
\hline & $\begin{array}{l}\text { Pensamientos respecto a una nueva posibili- } \\
\text { dad de trabajo productivo/reproductivo }\end{array}$ & & & & & & & & & & & & & & \\
\hline
\end{tabular}

\section{DISCUSIÓN}

Los significados del trabajo (MOW International Research Team, 1987) en las mujeres participantes del presente estudio se construyen a través de trayectorias laborales relacionadas con las vivencias alrededor del género (Guzmán \& Dalén, 2013), y la suplencia de las necesidades económicas. Las MTR, quienes tenían trayectorias laborales estables hasta que nacieron los hijos, toman la decisión en conjunto con sus parejas de dedicarse a la crianza de estos y el cuidado del hogar; en el caso de las MTP, tener hijos implicó requerir empleo para suplir necesidades en conjunto con su pareja, sin desligarse del rol tradicional atribuido al encargo de las labores reproductivas, mostrando que las negociaciones de pareja, en sus casos, no tiende necesariamente a la igualdad como lo manifiesta Agirre-Miguélez (2016).

Los significados del trabajo en las MTP se relacionan directamente con las funciones psicosociales del trabajo respecto a desarrollo de nuevas habilidades, contacto y relaciones interpersonales distintas del hogar, acceso a circuitos de consumo, confort, y estatus, entre otros (Luque, Gómez \& Cruces, 2000). Los significados del trabajo de las MTR por su parte, se asocian con el cuidado del hogar (alimentación, limpieza, cuidado durante la enfermedad 
de los miembros, acompañamiento a la educación de los hijos, entre otros), y la creación de vínculos y cuidado de los afectos, lo que tiene una relación directa con el trabajo reproductivo (Benería, 1981; Torns \& Carrasquer, 1987; D’Angelo, 2011); este en su mayoría es realizado por mujeres como reportan todas las participantes, y cuenta con poco o nulo reconocimiento social alrededor de ser considerado trabajo, como en efecto ocurre con las MTR quienes no lo representan de este modo (Vega, 2007; Baca, 2015; LoberaSerrano \& García-Sainz, 2014). Así mismo, el significado del trabajo en estas mujeres se relaciona con el apoyo al mantenimiento del hogar con actividades económico-productivas de subsistencia (Aguirre, 2003) como ventas por catálogo, entre otras, relacionando el trabajo reproductivo con actividades informales como lo afirma Chen (2012).

La centralidad del trabajo (MOW International Research Team, 1987) es mayor en las MTP que en las MTR; lo que puede deberse en alguna medida, a que las segundas no consideran su actividad como trabajo (Vega, 2007; Baca, 2015) y por la necesidad económica reportada por las que tienen TP (Peiró, Prieto \& Roe, 2002), así como por las funciones psicosociales ya mencionadas que el trabajo les proporciona (Luque, Gómez \& Cruces, 2000). También puede estar relacionada con que en sus trabajos productivos, han contado con hechos relevantes (Teixeira \& Carvalho, 2015) eventualmente positivos, que han marcado sus trayectorias laborales, y desean conservarlas, tales como reconocimiento en el trabajo, sentido de independencia económica e incluso intelectual y moral, según reportaron las entrevistadas.

Los derechos en las MTR están principalmente ligados al reconocimiento de sus actividades en el hogar, y los de las MTP, asociados con aspectos relativos al marco legal. Por esta misma línea, las mujeres con trabajo reproductivo expresan en sus narraciones las responsabilidades que ejercen en sus rutinas diarias y cómo se convierten en una carga laboral como cualquier otro trabajo hasta el punto de nombrarlas como un trabajo esclavizante, puesto que una jornada laboral para un ama de casa excede en promedio 16 horas diarias con labores que requieren desempeño físico y mental. Así mismo, respecto a dicha jornada expresan cierto tipo de "libertad" en sus horarios y cómo manejan su tiempo sin tener que rendir un informe o cuentas a un jefe o superior por lo realizado en el día, lo que de alguna manera funciona para las entrevistadas como una mediación simbólica del peso físico y psicológico que representa la labor extendida que realizan en el hogar. 
Las mujeres señalan que el trabajo en el hogar es "pesado", sin embargo, la compensación de tipo psicológico respecto a dichas jornadas se obtiene en su realización, lo que hace parte de sus derechos (MOW International Research Team, 1987), en primer lugar, la oportunidad de poder compartir la mayor parte del tiempo con sus hijos y pareja, garantizándoles así, una buena atención y un acompañamiento constante. A su vez es una manera de estar seguras de que las actividades hechas en casa están "bien hechas", según lo indican, ya que son ellas mismas quienes las realizan. Referente a esto, Vega (2007) establece que como el hogar no es visualizado socialmente como un lugar de producción, no es reconocido como trabajo ni a nivel macroeconómico ni en el imaginario colectivo. Sin embargo, se reconoce que esta modalidad de trabajo es imprescindible para el mantenimiento del espacio público, pero al realizarse en casa en espacios privados, no se ve y se da por supuesto que es una obligación (Larrañaga, Arregui \& Arpal, 2004).

Entre los deberes (de la dimensión normas sociales) reportados por las MTP, ellas destacan cada actividad laboral, pero relevando la necesidad de dedicar el tiempo para compartir con la familia, y evidenciando cómo se encargan de sus hijos a pesar del trabajo. Lo anterior puede relacionarse con que incluso ellas han asumido los aprendizajes relativos al género respecto a que las labores reproductivas son naturalmente atribuidas a las mujeres por su capacidad para cuidar, la delicadeza y la fertilidad (Castells, 1997; Vásquez, Cárcamo \& Hernández, 2012). Las MTR destacan como deberes todas las actividades que realizan durante el día en el hogar que consideran como su tarea, y reportan que desde niñas se les enseñó que las mujeres eran las encargadas de estas (Triana, Ávila \& Malagón, 2010).

Entre los valores laborales, las MTP desearían encontrar un trabajo con mayor autonomía, mejor salario, flexibilidad de horarios y mejores tratos comparados con los actuales. Reportan que estos ya les permiten cierto nivel de independencia económica y autonomía, así como acceso a relaciones distintas del hogar, aprendizaje y desarrollo de habilidades, lo que Bendassolli y Borgues (2011) reconocen como un trabajo más signficativo. Entre los valores de las MTR se destaca el interés por adquirir ganancias económicas para suplir las necesidades diarias y obtener mayor independencia económica.

Las MTP invitan a las MTR en general en sus narrativas a que trabajen productivamente para ganar independencia sin temor a la pérdida de pareja, lo que en alguna medida puede ser una transición respecto a la manera de representarse tradicionalmente la división sexual del trabajo, y asumir los deberes 
asignados por género, a una representación más contemporánea donde se dé por sentado que la pareja puede estar o no, sin que la mujer se encuentre estrictamente asignada a las labores de tipo reproductivo; sin embargo es de anotar a su vez que las MTP se siguen encargando principalmente de las labores del hogar, aunque cuenten al igual que los esposos con trabajos productivos, dejando ver que la representación se encuentra en transición y no ha sido transformada completamente.

Lo anterior, como lo describen Álvarez y Gómez (2011), muestra que al ingresar la mujer al campo laboral se le exige asumir un nuevo rol de carácter productivo, sin embargo manteniendo el viejo rol de cuidadora, lo cual explicaría los comentarios peyorativos por parte de algunas participantes con trabajos productivos hacia las mujeres con trabajo reproductivo, respecto de "ser mantenidas", así como lo manifestado por las MTR respecto a sentirse señaladas cuando las personas les insinúan que su trabajo es facilista por recibir los beneficios económicos de la pareja con la que conviven. El rol de la mujer ya no es solamente visto como el rol de cuidadora y responsable del hogar sino también como una mujer productiva que puede generar ingresos (Aguirre \& Martínez, 2006) implicando doble demanda y generando nuevas tensiones en la dinámica familiar (Álvarez \& Gómez, 2011).

Lo mencionado se manifiesta en las participantes con trabajo productivo quienes consideran este tipo de labor como una opción deseada y aceptada, mostrando a su vez gran centralidad del trabajo, y siendo enfáticas al señalar que rechazan una vida dedicada exclusivamente al trabajo reproductivo, pues entre otras razones, se percibe como algo monótono. Indicaron que el trabajo productivo les permite experimentar independencia, autonomía, y reconocimiento social, que son funciones psicosociales del trabajo (Luque, Gómez \& Cruces, 2000; Salanova, Gracia \& Peiró, 1996) que este tipo de actividad les permite gozar.

En el caso de las MTR con trabajos reproductivos por ejemplo, como ellas mismas lo expresan, se encuentran en situación de dependencia económica frente a su pareja, lo cual se convierte en una tema complejo en la medida en que no cuentan todas las veces con sus propios recursos para suplir, entre otras cuestiones, sus gustos personales. Lo anterior refuerza los planteamientos de Dakduk (2010), quien menciona que las mujeres con trabajo reproductivo enfrentan muchos retos, entre ellos el depender económicamente de alguien. 
Las MTR se dedican a acompañar y atender a los hijos, reportan satisfacción por la realización de dicha actividad. Las MTP realizan actividades reproductivas en el tiempo disponible; ellas reportan no tener la opción respecto a no trabajar. Como manifiestan Peiró, Prieto y Roe (2002), el trabajo se ha convertido en la fuente principal de ingresos y bienestar tanto para hombres como para mujeres, como lo muestran las MTP y las MTR que realizan labores de subsistencia. De acuerdo con Todaro (2015), las mujeres con trabajos productivos requieren mantenerse en estos por las exigencias económicas y búsqueda de autonomía, como en efecto lo reportan las participantes de este tipo de trabajo.

Así mismo la necesidad de las MTP por mantener un trabajo remunerado puede relacionarse con la exigencia social (Corina, 2005) alrededor de aportar económicamente al hogar, como es cada vez más común en parejas de doble ingreso (Aguirre \& Martínez, 2006), sin descargar o eliminar la responsabilidad sobre el trabajo reproductivo, lo que ocurre en lo reportado por las participantes.

Todas las participantes realizan actividades reproductivas, donde 8 de las 12 indican compartir las tareas con su pareja, sin embargo es explícito por su parte que asumen en gran medida la responsabilidad, incluso aquellas que además realizan trabajo productivo. Esto tiene relación directa con la división sexual del trabajo y las atribuciones respecto al género donde se asume que por ser el rol clásico, las mujeres siguen siendo las principales encargadas (Ajenjo \& García, 2011; Medialdea, 2016; Rodríguez, 2005; Guzmán \& Dalén, 2013) evidenciando inequidad con relación a este tipo de trabajo atravesado así mismo por nociones de género (Gómez, 2002; Todaro, 2015), siendo esto mencionado por las participantes y haciendo referencia a la doble jornada (Rodríguez, 2005; Guzmán \& Dalén, 2013) como lo reportan en particular las MTP.

Aunque las mujeres ocupan con mayor fuerza espacios de trabajo productivo, no ocurre lo mismo respecto a la ocupación de los hombres en trabajos reproductivos, a pesar que se considere que su participación es mayor que en épocas anteriores (Guzmán \& Dalén, 2013; Baca, 2015). Esto también puede estar mediado con que es el hombre quien aporta en gran medida a la economía del hogar, según reportan las participantes, con un porcentaje del $70 \%$ del dinero que se utiliza para la manutención, incluyendo el apoyo económico a ellas mismas. Pareciera que se asume que el aporte económico mayor al hogar, exime o reduce la responsabilidad sobre la participación 
masculina en las actividades reproductivas, lo cual se reporta como un pacto explícito en algunas pocas de las participantes, y como implícito en varias de ellas (Daros, 2014).

Finalmente, de acuerdo con Dakduk (2010) y Larrañaga, Arregui y Arpal (2004), las mujeres presentan menos posibilidades de discutir sobre la asignación del trabajo reproductivo comparadas con los hombres. Igualmente los resultados encontrados, en futuras investigaciones, pueden discutirse y cualificarse en función de otro tipo de categorías o variables como el estrato socioeconómico, nivel educativo de ambos miembros de la pareja, y nivel jerárquico del cargo desempeñado.

\section{CONCLUSIONES}

Las mujeres con trabajo reproductivo deciden dedicarse a este como una manera de responder a la demanda del rol tradicional asignado a la mujer, y por el deseo propio de acompañar el crecimiento de los hijos. Las mujeres con trabajo productivo afianzaron la necesidad de seguir vinculadas al mercado laboral para aportar al sostenimiento económico de la familia que incluye la llegada de los hijos, y deciden hacerlo por cumplimiento de funciones psicosociales.

El significado del trabajo de las mujeres con trabajo productivo gira alrededor del cumplimiento de funciones psicosociales que este le provee, más allá de la obtención de la ganancia económica, que aunque aporta a la suplencia de necesidades de esta naturaleza no termina siendo central; destacan particularmente la autonomía que provee lo económico. El significado de las mujeres con trabajo reproductivo se asocia principalmente al cuidado del hogar, aunque cuando se trata de la palabra trabajo no consideran la labor que realizan como tal.

Los derechos laborales de las mujeres con trabajo productivo están centrados en aspectos de naturaleza legal, y los de las mujeres con trabajo reproductivos ligados al reconocimiento de sus actividades, y a la libertad percibida respecto a la administración del tiempo y no tener un jefe que supervise el trabajo. Entre los derechos se encuentran, en el caso de las mujeres con trabajo reproductivo, dedicarse a las labores del hogar y hacerlas con calidad; las mujeres con trabajo productivo indican sus deberes desde las funciones que tienen asignadas en sus cargos, pero además destacan que su deber es 
también encargarse o responder por las labores que implique el cuidado y marcha del hogar.

Los valores laborales para las mujeres con trabajo productivo giran alrededor de incrementar el salario, los niveles de autonomía, flexibilidad horaria y mejora del trato. En el caso de las mujeres con trabajo reproductivo desean contar con un trabajo flexible, de pocas horas, y que les genere buenos ingresos para suplir necesidades diarias y contar con más independencia de sus parejas.

En general, las participantes reportan una nula o baja participación por parte de sus parejas y de los miembros del hogar relativas a las labores del trabajo reproductivo; incluso en sus narrativas cuando dicha participación aparece es representada como apoyo o ayuda, y no como una labor que debería ser compartida entre los dos miembros de la pareja, o de la familia.

Las mujeres con trabajo productivo invitan en sus narrativas a las de trabajo reproductivo a relacionarse desde esquemas más igualitarios de pareja relativos a las tareas reproductivas, incluso ellas mismas reportan encargarse principalmente de estas labores en sus hogares, mostrando que el cambio en la representación a una distribución más equitativa entre géneros respecto del trabajo reproductivo, está en un momento inicial o de transición. Resulta ser un pacto implícito, y en otros casos explícito entre las parejas, que el miembro que mayor aporte económico haga al hogar puede eximirse o reducir su responsabilidad de participar activamente de las actividades de naturaleza reproductiva.

Para futuras investigaciones se recomienda considerar otras variables que pueden influir o transformar los significados del trabajo en mujeres con trabajos productivo y reproductivo, como el estrato socioeconómico, el nivel de ingresos, y el nivel jerárquico del trabajo desempeñado e incluso la consideración de distintas modalidades de trabajo, no solo en calidad de empleo.

Financiación: Artículo derivado de la investigación titulada Significados del trabajo en mujeres con trabajos productivo y reproductivo en la ciudad de Cali, Grupo de investigación Bienestar, Trabajo, Cultura y Sociedad (BITACUS) de la Pontificia Universidad Javeriana Cali.

Agradecimientos: A las 12 participantes por compartir de manera abierta sus experiencias relativas al mundo del trabajo, y todas las cuestiones de género relacionadas con estas. 


\section{REFERENCIAS}

Abramo, L. (2004). ¿̇nserción laboral de las mujeres en América Latina: una fuerza de trabajo secundaria? Estudios feministas, 12(2) 224-235. http://www.scielo.br/ pdf/ref/v12n2/23969.pdf

Agirre-Miguélez, A. (2016). Negociaciones de pareja: los trabajos domésticos, la crianza y la construcción de la maternidad y la paternidad. Papeles del CEIC, 1(152), 1-27. http://dx.doi.org/10.1387/pceic.15209

Aguirre, R. (2003). Trabajo no remunerado y uso del tiempo. Fundamentos conceptuales y avances empíricos. La encuesta Montevideo 2003. Santiago de Chile: Comisión Económica para América Latina y el Caribe (CEPAL). https://repositorio. cepal.org/bitstream/handle/11362/5940/S055367_es.pdf?sequence=1\&isAllowed=y

Aguirre, R. (2007). Los cuidados familiares como problema público y objeto de políticas. En: I. Arriagada (Coord.), Familias y políticas públicas en América Latina (pp. 187-199). Santiago de Chile: Naciones Unidas. https://repositorio.cepal.org/ bitstream/handle/11362/2504/S0700488_es.pdf

Aguirre, Z., \& Martínez, M. P. (2006). Influencia de la situación laboral en el ajuste familia-trabajo. Mapfre Medicina, 17(1), 14-24. http://www.mapfre.com/ fundacion/html/revistas/medicina/v17n1/pdf/02_02.pdf

Ajenjo, M., \& García, J. (2011). El tiempo productivo, reproductivo y de ocio en las parejas de doble ingreso. Papers, 96(3), 985-1006. http://dx.doi.org/10.5565/ rev/papers/v96n3.183

Álvarez, A., \& Gómez, C. (2011). Conflicto trabajo-familia, en mujeres profesionales que trabajan en la modalidad de empleo. Pensamiento psicológico, 9(16), 89-106. http://www.redalyc.org/articulo.oa?id=80118612006

Andrade, V. (2014). Cambios en las relaciones de trabajo: Paradojas y consecuencias en el actual mundo del trabajo. Divers.: Perspect.Psicol. 10(2), 337-351. http:// www.scielo.org.co/pdf/dpp/v10n2/v10n2a11.pdf

Arce, R., \& Velarde, R. (septiembre, 2001). Descubriendo el significado que las mujeres asalariadas e informales le dan al trabajo en la ciudad de Santiago del Estero, Argentina. Trabajo presentado en XXIII Congreso Internacional de LASA del Instituto de Estudios para el Desarrollo Social (INDES), Santiago del Estereo. Recuperado de http://lasa.international.pitt.edu/Lasa2001/ArceRoxana.pdf

Baca, N. (2015). Desigualdades de género, trabajo reproductivo y mujeres migrantes. Reflexiones sobre el debate inconcluso. En D. Castillo, N. Baca \& R. Todaro (Coords.), Trabajo global y desigualdades en el mercado global (pp. 219-238). México D.F.: Universidad Autónoma del Estado de México. http://ri.uaemex. mx/bitstream/handle/20.500.11799/80277/Cap_Des\%20de\%20g\%C3\%A9nero_ NBT_Trabajo\%20Global.pdf?sequence=1\&isAllowed=y

Bardin, L. (2002). El análisis de contenido. Madrid: Akal.

Bassi, J. E. (2015). El código de transcripción de Gail Jefferson: adaptación para las ciencias sociales. Quaderns de Psicologia, 17(1), 32-62. https://doi.org/10.5565/ rev/qpsicologia.1252

Benavides, M. (2012). "Mujeres más allá de ángeles". Dinámicas familiares, participación ocupacional y social de mujeres que desempeñan el trabajo del cuidado. (Tesis de maestría). Universidad Nacional de Colombia, Colombia. http://www. bdigital.unal.edu.co/11091/1/870023.2013.pdf

Bendassolli, P., \& Borgues, A. (2011). Significado do trabalho nas indústrias criativas. Revista de Administracao de Empresas, 51(2), 143-159. http://dx.doi. org/10.1590/S0034-75902011000200003 
Benería, L. (1981). Reproducción, producción y división sexual del trabajo. Mientras tanto, 6, 47-84.

Blazsek, A. \& Saenz, M.V. (agosto, 2016). Cuando el trabajo reproductivo es trabajo productivo. El trabajo doméstico en discusión. I Jornadas nacionales de investigación en Ciencias Sociales de la UNCuyo. Argentina.

Castells, M. (1997). La era de la información: economía, sociedad y cultura (Vol. I). México D.F.: Siglo XXI.

Chen, M. (2012). La economía informal: definiciones, teorías y políticas. Wiego, 1(1), 1-22. http://www.wiego.org/sites/default/files/publications/files/Chen-Informal-Economy-Definitions-WIEGO-WP1-Espanol.pdf

Cohen, L \& Manion, L. (1990). Introducción: la naturaleza de la investigación. Madrid: Editorial La Muralla.

Corbetta, P. (2007). Metodología y técnicas de investigación social. Madrid: McGraw-Hill. https://diversidadlocal.files.wordpress.com/2012/09/metodologc3ada-y-tc3a9cnicas-de-investigacic3b3n-social-piergiorgio-corbetta.pdf

Corina, R. (septiembre, 2005). Economía del cuidado y política económica: una aproximación a sus interrelaciones. Trabajo presentado en Trigésima octava reunión de la Mesa Directiva de la Conferencia Regional sobre la Mujer de América Latina y el Caribe, Santiago de Chile. Recuperado de http://www.cepal.org/mujer/ reuniones/mesa38/C_Rodriguez.pdf

Cruz, A., Noriega, M., \& Garduño, M. (2003). Trabajo remunerado, trabajo doméstico y salud. Las diferencias cualitativas y cuantitativas entre mujeres y varones. Caderno de Saúde Pública, 16(4), 1129-1138. http://dx.doi.org/10.1590/ S0102-311X2003000400034

Dalla Costa, M. \& Selma, J. (1972). The Power of Women and the Subversion of the Community, Bristol: Falling Wall Press. Recuperado de: https://libcom.org/ files/Dalla\%20Costa\%20and\%20James\%20-\%20Women\%20and\%20the\%20 Subversion\%200f\%20the\%20Community.pdf

D’Angelo, F. (2011). El vínculo entre trabajo productivo y reproductivo en las trayectorias de mujeres jóvenes rurales. Revista Sociológica de Pensamiento Crítico, 5, 325-331. http://www.intersticios.es/article/view/8538/6262

Dakduk, S. (2010). Envejecer en casa: el rol de la mujer como cuidadora de familiares mayores dependientes. Revista Venezolana de Estudios de la Mujer, 15(35), 73-90. http://www.scielo.org.ve/scielo.php?script=sci_arttext\&pid=S1316-37012010000200005

Dakduk, S., González, A., \& Montilla, V. (2008). Relación de variables sociodemográficas, psicológicas y la condición laboral con el significado del trabajo. Interamerican Journal of Psychology, 42(2), 390 - 401. http://www.redalyc.org/articulo. oa? $\mathrm{id}=28442220$

Daros, W. (2014). La mujer posmoderna y el machismo. Franciscanum. Revista de las ciencias del espíritu, LVI(162), 107-129. http://www.redalyc.org/ pdf/3435/343532033005.pdf

Denzin, N. \& Lincoln, Y. (2000). Introduction: The discipline and practice of qualitative research. En N. Denzin \& Y. Lincoln (Edts), Handbook of qualitative research (pp. 1-28). London: Sage.

Departamento Administrativo Nacional de Estadística (DANE, 2018). Mercado laboral según sexo. Recuperado de: http://www.dane.gov.co/index.php/estadisticas-por-tema/mercado-laboral/segun-sexo

De Sousa, B. (1998). De la mano de Alicia. Lo social y lo público en la postmodernidad. Bogotá: Siglo del Hombre editores. Recuperado de: http://enlaceacademico.ucr. 
ac.cr/sites/default/files/publicaciones/DE\%20LA\%20MANO\%20DE\%20ALICIA_ Boaventura\%20de\%20Sousa.pdf

Drenth, P. (1991). Work meanings: A conceptual semantics and developmental approach. European Work and Organizational Psychologist, 1(2-3), 125-133. https://doi.org/10.1080/09602009108408517

Dubin, R. (1956). Industrial workers worlds: A study of the Central Life Interests of industrial workers. Social Problems 3, 131-142. https://www.jstor.org/ stable/799133?seq=1\#page_scan_tab_contents

Dubin, R. (1992). Central Life Interests: Creative individualism in a complex world. New Brunswick, New Jersey: Transaction Publishers.

Gammage, S. \& Orozco, M. (2008). El trabajo productivo no remunerado dentro del hogar: Guatemala y México. Serie Estudios y perspectivas. México D.F.: CEPAL. https://repositorio.cepal.org/bitstream/handle/11362/4882/1/S0800810_ es.pdf

Garazi, D. (2017). Las inestables fronteras entre el trabajo "productivo" y "reproductivo". Reflexiones a partir del trabajo en el sector hotelero. Trabajo y Sociedad, 29, 431-446. Recuperado de: http://www.unse.edu.ar/trabajoysociedad/29\%20 GARAZI\%20Trabajo\%20productivo_reproductivo.pdf

Gómez, E. (2002). Género, equidad y acceso a los servicios de salud: una aproximación empírica. Revista Panamericana de Salud Pública, 11(5-6), 327-334. http://dx.doi.org/10.1590/\$1020-49892002000500008

Gorz, A. (1995). Metamorfosis del trabajo. Madrid: Sistema.

Guzmán, D.E., \& Dalén, A. (2013). Entre estereotipos. Trayectorias laborales de mujeres y hombres en Colombia. Bogotá: Centro de estudios de Derecho, Justicia y Sociedad, Dejusticia. Recuperado de: https://www.dejusticia.org/wp-content/ uploads/2017/04/fi_name_recurso_601.pdf?×54537

Herrera, P. (2000). Rol de género y funcionamiento familiar. Revista Cubana de Medicina General Integral, 16(6), 568-573. Recuperado de: http://scielo.sld.cu/ scielo.php?script=sci_arttext\&pid=S0864-21252000000600008

Hochschild, A. (1983). The managed heart: commercializaction of human feeling. Berkeley and Los Angeles: University of California Press.

Joplin, J., Francesco, A. M., Shaffer, M. A., \& Lau, T. (2003). The macro-environment and work family conflict. International Journal of Cross Cultural Management, 3(3), 305-328. https://doi.org/10.1177/1470595803003003004

Larrañaga, I., Arregui, B., \& Arpal, J. (2004). El trabajo reproductivo o doméstico. Gaceta Sanitaria, 1(18), 17-21. http://dx.doi.org/10.1590/S0213-91112004000700007

Lobera-Serrano, J. \& García-Sainz, C. (2014). Identidad, significado y medición de las amas de casa. Quaderns de Psicologia, 16(1), 213-226. http://dx.doi.org/10.5565/ rev/qpsicologia.1193

Long, Z. (2016). A Feminist Ventriloquial Analysis of Hao Gongzuo ("Good Work"): Politicizing Chinese Post-1980s Women's Meanings of Work. Women's studies in communication, 39(4), 422-441. Tomado de: https://www.tandfonline.com/doi/ full/10.1080/07491409.2016.1224991

Luque, P. J., Gómez, T., \& Cruces, S. J. (2000). El trabajo: fenómeno psicosocial. En C. Guillen \& R. Guil (Eds.), Psicología del trabajo para relaciones laborales (pp. 147-163). Madrid: McGraw-Hill.

MOW International Research Team. (1987). The meaning of working. An International View. London: Academic Press. 
Medialdea, B. (2016). Discriminación laboral y trabajo de cuidados: el derecho de las mujeres jóvenes a no elegir. Atlánticas. Revista Internacional de Estudios Feministas, 1(1), 90-107. http://dx.doi.org/10.17979/arief.2016.1.1.1792

Ministerio de Salud (1993). Resolución No. 008430 de 1993. Recuperado de https:// www.minsalud.gov.co/sites/rid/Lists/BibliotecaDigital/RIDE/DE/DIJ/RESOLUCION-8430-DE-1993.PDF

Montaño, S. (2007). El sueño de las mujeres: democracia en la familia. En: I. Arriagada (Coord.), Familias y políticas públicas en América Latina (pp. 139-147). Santiago de Chile: Naciones Unidas. https://repositorio.cepal.org/bitstream/ handle/11362/6780/S0412955_es. pdf?sequence=1\&isAllowed $=y$

Morse, J. (1995). The significance o saturation. Qual health res, 5(2), 147-149. Recuperado de http://qhr.sagepub.com/content/5/2/147.full.pdf

Neffa, J. C. (2003). El trabajo humano: contribuciones al estudio de un valor que permanece. Buenos Aires: Lumen Press.

Peiró, J., Prieto, F., \& Roe, R. (2002). La aproximación psicológica del trabajo en un entorno laboral cambiante. En J.M. Peiró \& F. Prieto (Dirs.), Tratado de Psicología del trabajo (pp. 15- 36). Madrid: Síntesis, SA.

Quintanilla, S., \& Wilpert, B. (1991). Are work meanings changing? European Work and Organizational Psychologist, 1(2/3), 91-109. https://www.tandfonline.com/ doi/abs/10.1080/09602009108408515?journalCode=pewo19

República de Colombia (2006). Ley 1090 de 2006. Recuperado de http://www.secretariasenado.gov.co/senado/basedoc/ley_1090_2006.htm/revistas.iberoamericana.edu.co/index.php/ripsicologia/article/download/250/218

Rodríguez, C. (2005). La economía del cuidado: un aporte conceptual para el estudio de políticas públicas (Informe No. 44). Buenos Aires: Centro Interdisciplinario para el Estudio de Políticas Públicas. http://docplayer.es/16916322-No-44-la-economia-del-cuidado-un-aporte-conceptual-para-el-estudio-de-politicas-publicas-corina-rodriguez-enriquez-buenos-aires-mayo-de-2005.html

Rokeach, M., \& Regan, J. (1980). The role of values in the counseling situation. Personal and Guidance Journal, 58(9), 576-582. https://doi.org/10.1002/j.2164-4918.1980. tb00454.x

Ruíz-Pérez, I., Plazaola-Castaño, J., \& Montero-Piñar, M.I. (2011). The relationship between reproductive work and sociodemographic and psichosocial factors in regard to psychological distress in mena an woman in Spain. Prev. Sci., 12, 423-434. https://www.ncbi.nlm.nih.gov/pmc/articles/PMC3839342/

Ruiz-Quintanilla, A., \& Wilpert, B. (1991). Are work meanings changing? European Work and Organizational Psychologist, 1(2/3), 91-109. https://10.1080/096020 09108408515

Salamanca, A., \& Crespo, C. (2007). El muestreo en la investigación cualitativa. Nure investigación, 1(27), 1- 4. Recuperado de: http://ceppia.com.co/Documentos-tematicos/INVESTIGACION-SOCIAL/MUESTREO-INV-CUALITATIVA.pdf

Salanova, M., Gracia, F.J. \& Peiró, J.M. (1996). Significado del trabajo y valores laborales. En J. M. Peiró, \& F. Prieto (Eds.), Tratado de psicología del trabajo. Vol. II: Aspectos psicosociales del trabajo (pp. 35-63). Madrid: Síntesis S.A. Recuperado de: https://www.researchgate.net/publication/317412727_Significado_del_trabajo_y_valores_laborales

Salgado, L.A. (2007). Investigación cualitativa: diseños, evaluación del rigor metodológico y retos. Liberabit, 13, 71-78. Recuperado de: http://www.scielo.org.pe/ scielo.php?script=sci_arttext\&pid=S1729-48272007000100009 
Schwartz, S.H., \& Bilsky, W. (1987). Toward a universal psychological structure of human values. Journal of Personality and Social Psychology, 53(3), 550-562. https://www.researchgate.net/publication/228079314_Toward_A_Universal_ Psychological_Structure_of_Human_Values

Spink, M.J. (2013). Práticas discursivas e produção de sentidos no cotidiano aproximações teóricas e metodológicas. Rio de Janeiro: Centro Edelstein de pesquisas sociais. file:///C:/Users/000133596/Downloads/SPINK_Praticas_discursivas_e_ producao_FINAL_CAPA_NOVAc.pdf

Teixeira, K.A., \& Carvalho, M. (2015). Sentidos do trabalho apreendidos por meio de fatos marcantes na trajetória de mulheres prostitutas. Revista de Administração Mackenzie, 16(6), 19-47. http://www.scielo.br/scielo.php?script=sci_arttext\&pi$d=S 1678-69712015000600019 \&$ Ing=en\& $n r m=i s o \& t \mid n g=p t$

Todaro, R. (2015). Flexibilidades, rigideces y precarización: Trabajo remunerado y trabajo reproductivo y de cuidado. En D. Castillo, N. Baca \& R. Todaro (Coords.), Trabajo global y desigualdades en el mercado global (pp. 185-202). México D.F.: Universidad Autónoma del Estado de México.

Torns, T., \& Carrasquer, P. (1987). Entorn dels conceptes de dona i treball a Catalunya. A: Visió de Catalunya. Barcelona: Diputació de Barcelona.

Triana, A., Ávila, L., \& Malagón, A. (2010). Patrones de crianza y cuidado de niños y niñas en Boyacá. Revista Latinoamericana de Ciencias Sociales, Niñez y Juventud, 8(2), 933-945. http://www.redalyc.org/pdf/773/77315155012.pdf

Vásquez, V., Cárcamo, N., \& Hernández, N. (2012). Entre el cargo, la maternidad y la doble jornada. Presidentas municipales de Oaxaca. Perfiles Latinoamericanos, 39, 31-57. http://www.redalyc.org/articulo.oa?id=11523035002

Vega, A. (2007). Por la visibilidad de las amas de casa: rompiendo la invisibilidad del trabajo doméstico. Política y Cultura, 28, 173-193. http://www.redalyc.org/ articulo.oa?id=26702808

Veloz, C. (2010). Mujeres Purépechas en las maquiladoras de Tijuana: Entre la flexibilidad y significación del trabajo. Frontera norte, 22(44), 211- 236. http://dx.doi. org/10.17428/rfn.v22i44.858

Venegas, C. (2010). Realidad laboral de la Psicología en Chile y la región: ¿libre mercado o dignidad humana? Razón y Palabra, 72, 1-56. http://www.razonypalabra.org.mx/N/N72/Varia_72/19_Venegas_72.pdf 